country where there is no lack of agricultural land is being strongly opposed by both French naturalists and sportsmen and their colleagues in other countries.

The proposals concerning the establishment of Council of Europe machinery for matters concerning nature conservancy and national parks were considered, and the prospect of a closer relationship between the Council of Europe and organizations for conservation of Nature was welcomed.

Among other subjects discussed were the traffic in European birds for cageing, bird protection in schools, the danger of the airgun and the increase of the starling (Sturnus vulgaris).

Prof. Sven Hörstadius (Sweden) was unanimously elected chairman of the European Continental Section in succession to Dr. Bøje Benzon (Denmark), and Dr. Gerth von Rokitansky (Austria), vice-chairman, in succession to Dr. G. A. Brouwer (Netherlands). Prof. S. O. Hörstadius, a former president of the International Union of Biological Sciences, was accorded an honorary degree by the University of Cambridge during the tercentenary celebrations of the Royal Society in 1960, and it may be apt to quote the Orator's citation on this occasion:

"We read in Lucretius these lines about the origin of animals: 'And many monsters also did the earth then try to ereate, springing up with strange face and limbs'. She did so to no purpose. But this man does the same to very good purpose. For beginning his studies from the egg in no mere proverbial sense, and using incredible penetration of mind and dexterity of hands alike, he has taken to pieces, down to their smallest components, the embryos of sea-urchins, worms and amphibia, and then re-assembled these into new animal organisms. Would anyone have believed before that two tissues cut from an embryonic newt combined could co-operate to form cartilage, and that, with the addition of a third, tooth would result ? What wonderful metamorphoses, and advantageous indeed to men! For from this he has thrown light on the influence of part upon part and organ upon organ in the gradual construction of the adult animal, which could be of great value to the art of medicine. So we salute one who has at last set foot on the true way in an inquiry raised by Aristotle himself.

"But do not imagine he only examines and handles eggs. For he is an observer of the ways of birds, and in that most pleasant branch of study also has won world-wide fame.

"I present to you a professor of Uppsala, worthy heir of the studies of Linnæus of Uppsala-Sven Otto Hörstadius".

Phyllis Barclay-Smith

\title{
IMMUNITY TO PROTOZOA
}

$\mathrm{I}_{\text {of }}^{\mathrm{N}}$ $\mathrm{N}$ the age of Metchnikow and Ehrlich, the subject of immunity had not become divided into the separate compartments of bacteria, fungi, protozoa, etc., as it has to-day, and a broader view was possible at that time. A recent symposium, organized by the British Society for Immunology at the Middlesex Hospital during June 1-2, represented an attempt by the Society to reverse the trend and to bring workers of one specialized field (protozoology) into the classical milieu. Various aspects of immunity to protozoa were thus presented, and, to some extent the idea of the Society was successful, many interesting papers were given, and these provoked some discussion.

The subject of the symposium, "Immunity to Protozoa", was introduced by P. C. C. Garnham, who gave a short historical survey, then a summary of the histological basis of immunity and finally a review of acquired and innate immunity in the parasitic protozoa. In his opinion, the realm of innate or natural immunity offered at present the most promising opportunities for research. All degrees of resistance of the host to the organism are found, which may be influenced by various internal factors like unsuitable blood components (later ably described by A. C. Allison in regard to the inhibitory action of sickle-cell hæmoglobin and glucose-6dehydrogenase deficiency on Plasmodium falciparum), by external factors like removal of the spleen, and lastly by the site occupied by the parasite in relation to its host: immunity thus may be unable to touch the parasite when it is safely enclosed within a paren. chyma cell of the liver, yet immunity will kill rapidly when it lies in an exposed position in the blood stream.

The symposium was honoured by the presence of Edmond Sergent, who came from Algiers to give a lucid account of premunition, a subject which has occupied him for the past 60 years and which he here crystallized into 26 precise definitions. Premunition is the basis of the subject, and yet has been much misunderstood; it was useful to have it described by the Martre himself. On the other hand, premunition is not the only form of immunity, and A. Corradetti deseribed examples of true residual immunity in rats which had recovered from Plasmodium berghei and Trypanosoma lewisi infections respectively; in some cases, nothing could break down this resistance, and he clearly showed that the protozoa had been completely eliminated by the immunity response, while the rats proved to be immune for life.

Much of the original work on the cellular basis of immunity was carried out by W. H. Taliaferro, by his wife Lucy, and his collaborator, H. Mulligan. All these workers were present at the symposium, and the subject was introduced by W. H. Taliaferro, who described briefly the lymphoid-macrophage system and then went on to more recent work of a biochemical nature. This indicated that under the influence of the growth-inhibitory antibody, 'ablastin', nucleic acid synthesis in T. lewisi comes to a stop, although protein synthesis may continue at a low level. He also considered the phenomenon of 'avidity' or antigen-binding capacity. His explanation of the development of immunity in $T$. lewisi infections by the successive appearance of several different types of antibody was challenged by W. E. Ormerod, who suggested that the disappearanee of young and dividing forms (the earliest of which inhabit the protected environment of the kidney capillaries) was not due to 'ablastin' but to an ordinary type of antibody which had a selective action on the young forms.

The subject of immunity cannot properly be considered apart from the nature of the damage inflicted 
by the parasite on the host, in other words, the mechanism of pathogenicity. B. G. Maegraith illustrated this by reference to non-invasive strains of parasites, which later change their habits and attack the tissue so that an increasing degree of virulence is attained. In Entamoeba histolytica, the special enzyme production of an amoeba determined its pathogenic potential. The actual cause of injury was thought, in the case of malaria, to be a soluble toxin which acted on the mitochondria of cells, destroyed their membranes, and brought respiration to an end. The chemical composition of this agent is still not precisely known, but it appears to be non-specific. This work seems to be on the brink of important new discoveries.

The symposium then continued by examining the phenomenon of immunity in: $(a)$ blood infections; (b) tissue infections; (c) infections of the skin and mucous membranes, including the intestinal tract. The last-mentioned group stood out from the rest because some localization of immunity was often apparent.

Immunity in malaria was discussed by Avivah Zuckerman. In vitro, macrophages exposed to malarious chicken blood, in the presence of hyperimmune homologous serum, phagocytosed numerous normal as well as parasitized erythrocytes. Furthermore, in a series of simian, rodent and avian malarias, more anæmia occurred than could be attributed to destruction of red cells by emerging parasites. An autoantibody was postulated to explain these observations, and Coombs' tests were positive in two rodent malarias during the period of excessive anæmia. However, since positive antiglobulin tests were also observed in other anæmic states from which parasites were absent, the autoantibody hypothesis remains moot.

L. J. Bruce-Chwatt gave an interesting account of the variability of immunity in malaria inherited by an infant from its mother, and which might be derived either via the placenta (particularly in human beings) or via the milk (in rodents). There was no doubt of its existence in the hyperendemic regions of tropical Africa, and it formed a valuable barrier to infection in the earliest days of life, though the effect quickly wears off. Transplacental immunity is probably the explanation of the unexpectedly low rates of occurrence of parasites in infancy. The exact mechanism is still unknown, and it was suggested that the subject might be investigated further in monkeys, where the placental structure was not unlike that of the human.

Immunity in piroplasmosis was considered by R. Riek, and in a written communication by $\mathbf{S}$. $\mathbf{F}$. Barnett. The former described babesiosis in Australian cattle, demonstrating once more the peculiar tolerance of calves to Babesia infections in contrast to the susceptibility of the adults. He made some interesting references to the pathogenic effect of this organism, when present in a high density, on the invertebrate host, a subject which had been little discussed, perhaps because the arthropod is normally immune to any harmful effects of the protozoon which it carries. S. F. Barnett divided the Theileria species in eattle into three immunological groups: (1) $T$. mutans ; (2) $T$. annulata; (3) $T$. parva (which includes lawrencei and bovis in addition to parva). The last-mentioned group behaves differently because it produces a sterile residual immunity while the other two are followed by premunition. This worker stated that the endoglobular parasites and the intra. lymphocytic schizonts gave rise to distinct antibodies, and that after recovery from an endoglobular infection, the animal was still susceptible to the tissue forms, which were finally destroyed by lytic antibodies.

Immunity in trypanosomiasis was discussed in four papers. B. Weitz described his recent researches on exo-antigens in infections with the African trypanosomes. K. N. Brown analysed the antigens of $T$. rhodesiense, a highly labile organism which resorts to many changes in antigenicity, though reverting to the parent type after passage through Glossina. Two groups of antigens can be distinguished chemically by starch-gel electrophoresis and by ultracentrifugation ; one type is predominantly protein, the other is of unknown composition. This chemical approach has scarcely gone far enough yet for conclusions or principles to be drawn, but it offers promise for the future, especially when combined with the agar techniques using double diffusion of separating strains. A paper by M. A. Soltys and C. S. Folkers was presented by the latter and dealt with the effect of immunity on chemotherapy and chemoprophylaxis of the African trypanosomes of veterinary importance.

Two papers were given on toxoplasmosis. The first, by J. D. Fulton. gave a useful summary of the immunity reactions in this disease, and included details of the author's new agglutination test, using washed organisms from mouse peritoneal fluid. The results of this test corresponded closely with those of the Sabin-Feldman reaction, were constant, easy to read, and beset with none of the difficulties of the dye test. C. P. Beattie discussed the prevalence of the infection throughout the world in man, in other mammals and birds; but Toxoplasma gondii is a welladapted parasite which rarely causes much pathogenicity to its host, either because most strains are of naturally low virulence or because of some special insuseeptibility of the host. Youth, concomitant illness, and physical stress are factors which predispose to multiplication of the organism. Although several antibodies have been shown to exist in chronic infections, it is strange that none is particularly adequate in destroying the organism, perhaps because it eventually becomes enclosed in a cyst with an impermeable wall. But man has a natural resistance to the infection, which may be of the nature of premunition, the organism persisting in a latent form for years, and resembling in this and other aspects the tubercle bacillus.

Saul Adler described immunity in leishmaniasis, and discussed chiefly the reaction of man to the various eutaneous forms of Leishmania. He made a plea for the recognition and separation of these organisms into sub-species, of which there were two in the old World and at least four in Latin America, causing the classical espundia in Brazil, uta in Peru, chiclero's disease in Central America and a curious form in Venezuela. These were distinct clinical entities, had special sandfly vectors, particular animal reservoirs, characteristic response to drugs and specific antibody reactions by which each form could be distinguished readily. He directed attention to the paradox of a protozoon making its home in cells of the lymphoid-macrophage system, the system which, par excellence, protects the host from protozoal infections. Nevertheless the host wins, and a persistent sterile immunity is the result. 
Adler's paper formed a good introduction to the last part of the symposium, which concerned parasites localized in the skin or mucous membranes. The immunity reactions of this group have a peculiarly focal restriction, in contrast to the ordinary antibody response when the infection is generalized; but the difference disappears if these localized parasites are introduced artificially into the blood stream of the host, when a typical antibody reaction is the result. Muriel Robertson showed, however, that such antibodies, produced in response to Trichomonas foetus, were unable to reach the flagellates in their protected sites in the uterine wall; the production of antibody is a sequence of the presentation of antigen to the appropriate host cells; in trichomoniasis of cattle the antibody had a very limited value in destroying the infection.

C. Horton-Smith, P. L. Long, A. E. Pierce and M. E. Rose also examined the question of local immunity in coccidiosis and showed that a fowl which had recovered from an infection of Eimeria tenella in one cæcum was nevertheless immune in the other. These workers demonstrated that different stages of the life-cycle of coccidian parasites had their specific immunizing values. R. Augustin and A. P. Ridges. described similar work on $E$. meleagrimitis of turkeys.

In the early days, immunologists were much concerned in the practical aspects of cure or prophylaxis of disease: two papers in the present symposium show that this subject is still of interest to-day. S. Cohen and I. A. MeGregor gave a most interesting account of the use of gamma-globulin in the cure of malaria. They collected sera from hyperimmune adults living in the Gambia and extracted the gamma-globulin component; this was then given in large doses to young children who were suffering from acute infections of the disease. Within 4 days, parasitæmia fell and by the ninth-day parasites were undetectable in 8 of the 12 cases studied. These investigations were accompanied by work on the turnover of gamma. globulin, on the lessening of hypergamma-globulinæmia as the result of specific therapy, etc., all of which observations tend to indicate that humoral immunity may be more important in malaria than was originally thought. The antibody appears to be contained in the 7-S fraction and not in the macroglobulin. P. E. C. Manson Bahr sent an important communication on a big field experiment he is carrying out in Kenya, in which he has immunized a population which is exposed to epidemic kala-azar with an avirulent ground squirrel strain of the organism. Preliminary work had shown that volunteers could be protected in this way.

The papers are being published in book form, and this should provide a modern review of many important aspects of the subject. P. C. C. GarnhaM

\section{THE MUSEUMS ASSOCIATION}

$\mathrm{I}^{\mathrm{N}}$

$\mathrm{N}$ the ideal environment of the City of Plymouth and its museums the sixty-seventh annual conference of the Museums Association was held during June 19-23, 1961.

The conference was officially welcomed by the Lord Mayor and this was followed by the presidential address by Dr. D. B. Harden (London Museum). In an interesting historical survey of the continual efforts of the Museums Association since 1945 to obtain Government grants for the provincial museums - and especially the smaller ones - he felt that there had been a certain amount of progress, for at last the Standing Commission for Museums and Art Galleries had been instructed to prepare a report. This was awaited with interest, though, meanwhile, the Associa tion and museums throughout Britain were grateful to the Carnegie United Kingdom Trust for its continual help and advice. Reference was also made to the formation of the Area Councils and especially to the progress made by that in the south-west.

Sir Hugh Casson opened the discussion on display in museums, and in a provocative and entertaining address said that a lively imagination was necessary both in new buildings and in the adaptation of the older ones. He stressed that the building and display must be shared by the curator and the architect, and that it was essential to establish character and personality in a museum. A museum must be an active place-a lively cultural centre to arouse the sense of the curious.

Dr. D. A. Allan felt that the ideal display of natural history objects should include the clinical and the artistic. He also stressed the value of genuine objects, and said that it was important to achieve liveliness and realism. Large dioramas were not in the fashion at the present day. Mr. J. W. Y. Higgs (University of Oxford) dealt chiefly with folk material, and detailed the value of comparative displays-doing the same thing in different ways. $\mathrm{He}$ also referred to the need for more folk parks in Britain. Mr. Norman Cook (Guildhall Museum) stated that it was necessary to serve the public at different levels. $\mathrm{He}$ also felt that not all archæological exhibits should be treated as works of art, for it was not the curators' task to make everything look beautiful. As chairman of this session, Sir Frank Francis (British Museum) felt that there was no single solution to the problem of display for museums were both for the connoisseur and the ordinary visitor. The future may lie in some form of double exhibition.

A whole day was devoted to the many problems of conservation. Dr. P. Coremans (Brussels) opened the discussion, and said that great changes in the treatment of paintings was due to the scientific interest now taken in this subject. He described methods whereby it was possible to distinguish the layers of dirt, re-paint, varnish and the glazes which were an integral part of the picture itself. The extreme differences of opinion regarding restoration were also discussed. Mr. Norman Bronmelle (Victoria and Albert Museum) suggested a scheme for making modern scientific resources available to provincial museums, and Mr. H. Schubart (Bristol) spoke about the training of picture restorers. An art school basis was probably the best, but the creative impulse of the restorer must be directed entirely to conservation so that the welfare of the object became second nature.

An afternoon session was devoted to a symposium on modern developments of conservation in museums as opposed to art galleries. Dr. A. E. Werner 